\title{
FUNDAMENTAL INVESTIGATION OF THE OIL/WATER FLOW EMULSION IN THE DOWNHOLE BY CFD SIMULATION
}

\author{
HUSSAIN H. AL-KAYIEM \& IYLIA E. A. JAMIL \\ Mechanical Engineering Department, Universiti Teknologi PETRONAS, Perak, Malaysia
}

\begin{abstract}
Downhole oil/water separation methods are based on hydrocyclone technique. Most of the related investigations have a focus on the flow structure inside the cyclone. There is a lack of studies and simulations on the wellbore flow pre-and post-separation. The current computational simulation of the oil/water flowing inside wellbore before and after separation by counter current hydrocyclone. The emulsion of oil/water in the well production and dumping zones in the downhole, was simulated using ANSYS-Fluent 14 software and it was attempted to visualize the volume fraction profiles, density distribution profiles and the flow patterns in a real downhole environment. The well geometries and the oil/water production candidates at the downhole have been adopted from a real well in an offshore field in Malaysia. The results illustrated the great complexity of oil/water flows, reflecting the many competing processes; e.g. turbulence, gravitational separation, droplets interaction and the shear between the two liquids and with the solid surfaces. The simulation results in the production zone indicate that distribution of the oil volume fraction depends highly on the mean oil volume fraction. The contour results showed that the phases mix and achieve uniform distribution as the flow proceeds down the annulus. The achieved simulation results will contribute to better forecasting of the behaviour of oil/water mixture inside the wellbores with the presence of a hydrocyclone with one or multi inlets. Keywords: complex flow structure, downhole, DOWS, oil and water flow, two-phase simulation.
\end{abstract}

\section{INTRODUCTION}

In any method of downhole oil/water separation (DOWS), the oil is lifted to the surface and water is re-injected into the reservoir formation, or disposed into the sea after costly treatment to meet the environmental regulations. Handling the problem of water produced with oil has a large concern by the O\&G industry, the R\&D bodies, as well as the academic researchers. Water-in-oil is the largest volume waste stream associated with oil production which is unavoidable in mature fields. Produced oil is usually escorted by an underlying aquifer. As the well production is increasing, water-in-oil content also increases and may reach a point of breakthrough into the wellbore. The water breakthrough, or water coning, might happen because of the high pressure round the wellbore. Water has higher mobility than oil, where water viscosity is much lower than oil, hence, relative permeability of water is much larger than oil. Large amount of water-in-oil production leads to high operation expenses, high cost to dispose the produced water, and larger environmental risk. Also, additional requirement to lift the produced water is representing additional cost. Shaw and Fox [1] recognized that increasing water production in O\&G wells as the single leading contributor to declining profitability in oil production. Ouyang and Aziz [2] and then, Ahmed and Ayoub [3] demonstrated that production of water-in-oil may also margin the well production life via fines migrations. In addition, high water-in-oil production hinders oil production to production pipes, hence causing low recovery at oil layer.

Treatment and disposal of produced water represent significant costs for operators. In the recent decade, there is growing recognition for the need of a controlled water production to meet the immense challenges of increasing water handling cost and to extend the life of the well especially at offshore operation. Introduction of new technologies like Intelligent 
Completions-which allows real time measurements of water breakthrough (Tubel and Herbert [4]), suppressed coning (Swisher and Wojtanoviez [5]) and Downhole Oil-Water Separation (DOWS) give an added advantage to controlling water production as they present no risk to productivity, unlike gels and cement (Shaw and Fox [1]).

\section{DOWNHOLE OIL-WATER SEPARATION}

DOWS technology is a hydrocyclone-based system for downhole separation of produced oil/water and subsequent disposal of the produced water by reinjection. It works with the combined use of static hydrocyclone and conventional Electrical Submersible Pumping systems (Shaw and Fox [1]). However, concomitant with the presented simulation study of the oil/water emulsion in this paper, is the utilisation of DOWS without usage of electric submersible pump (Yin et al. [6]). Theoretically such concept requires relative positioning of the zones of a high-pressure production layers on top and a low-pressure water zone below to complete the hydro cyclonic separation.

Initially, the implementation and trials of the DOWS system were targeted on wells of little value, low production rate and high water cut. With success and potential for bigger profit in adopting DOWS, the system implementation has highlighted many areas for development, one of which is the completion design for reinjection, or dumping of water back into the reservoir. Some of the requirements of water-reinjection include the presence of a suitable dumping zone that is isolated from the producing zone, compatible water chemistry between the producing and dumping zones and properly constructed well with good mechanical integrity. Problems in existing systems expose insufficient distance between the producing and the dumping interval, which allow the injected fluid to migrate into the producing zone, causing corrosion or scaling because of incompatible chemistry between the produced and injected fluids and excessive sand production that cause clogging of formation (Veil and Quinn [7]).

Bowers et al. [8], concluded that because of the high uncertainty surrounding the injectivity index of the dumping zone, it is beneficial to study the behaviour of water flow, with little amount of oil after exiting the separator inside the wellbore. The recommendation for the necessity of studying the oil/water mixture behaviour is also confirmed by Yin et al. [6]. Thus, for better forecast the behaviour of the mixture entering the LLHC separator, a step back has been taken to study the behaviour of the oil/water mixture flow inside the wellbore. This, in fact, is the driving initiative to conduct the present simulation, where most of the previous studies are conducted on economic base rather than technical base. Studies that are technical base focus only on the separator and not the flow field structure.

The objective of this investigation is to simulate and analyze the flow structure of the oil/water mixture in the downhole with presence of LLHC separator. CFD has been adopted to obtain quantitative and qualitative portrayal of the oil/water flow behaviour from the reservoir into the wellbore, which is the pre-separation flow and from the wellbore back into the reservoir, which is the post-separation flow. The wellbore was modelled as $3 \mathrm{D}$ and simulated by ANSYS-Fluent 14 software. The fluids properties have been advocated from a real offshore oil field in Malaysia. Four cases of oil/water production ratios have been considered for the production zone as $30 \%, 50 \%, 70 \%$ and $90 \%$ oil content.

\section{DOWNHOLE MODEL FORMULATION}

The design configuration of the wellbore have been depicted from a real well where production occurs in the upper zone and the dumping is in the lower zone, as depicted schematically in Fig. 1. 


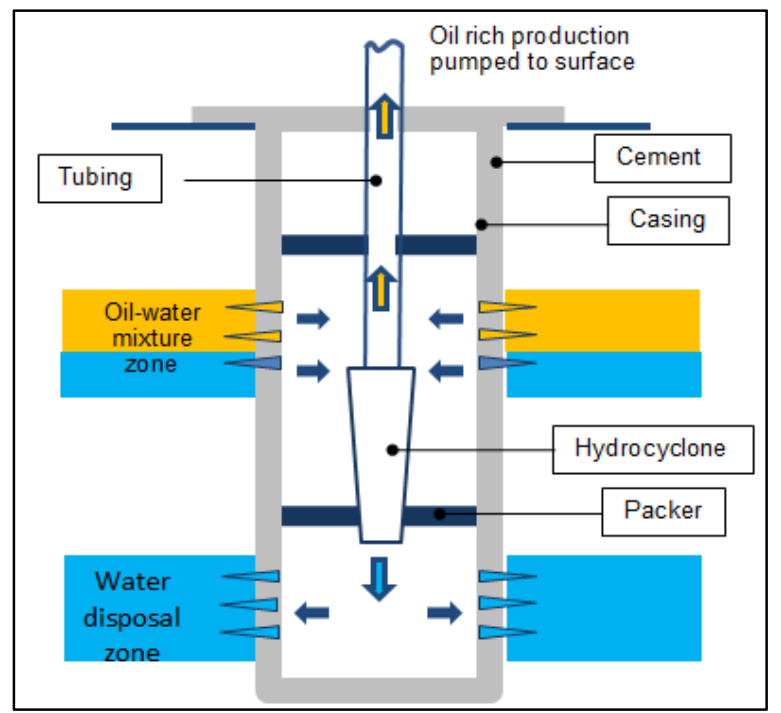

Figure 1: The wellbore model.

Works on the LLHC separation zone and the hydrodynamic behaviour of fluids in the system may be referred to Yin et al. [6], Harrison et al. [9], [10]. The wellbore model has been broken down into three separate parts. Fig. 2(a) is the upper zone, which is the production zone, with high pressure. Fig. 2(b) is the lower zone, which is the dumping zone, with lower pressure. The third part is the hydrocyclone separator. The numerical investigation presented in this paper considers on the upper zone and the lower zone flow fields. Fig. 2(a) and 2(b) give a clear representation of the inlets and outlets of these zones. For the production zone.

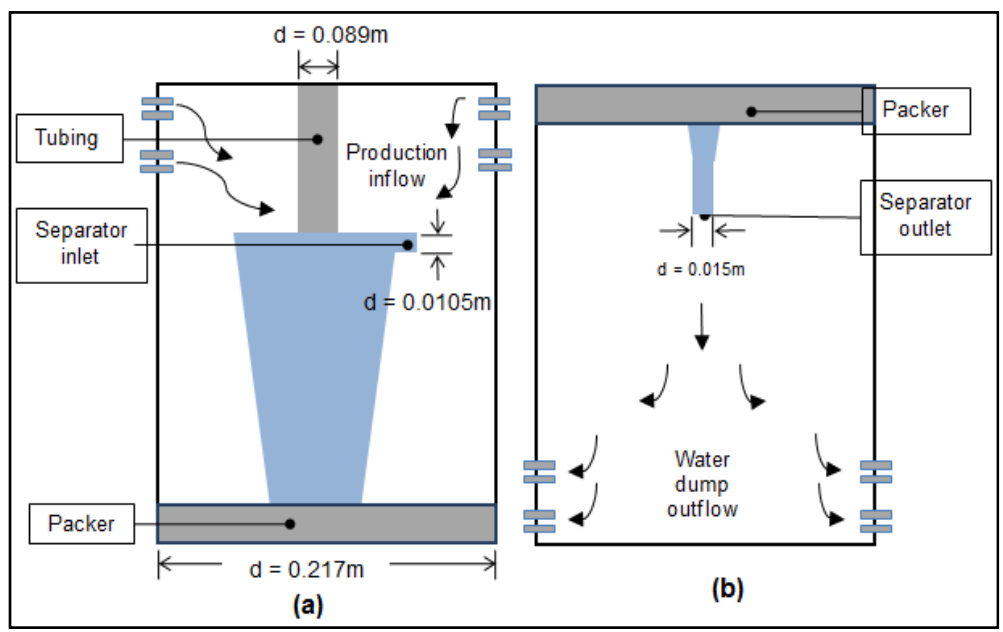

Figure 2: Sketches of the zones in the wellbore. (a) The upper zone; (b) The lower zone. 
Table 1: Design parameters of the production and dumping zones

\begin{tabular}{|c|c|}
\hline Parameter & Value \\
\hline Casing OD & $0.244 \mathrm{~m}\left(95 / 8^{\prime \prime}\right)$ \\
\hline Casing ID & $0.217 \mathrm{~m}(8.535 ”)$ \\
\hline Casing wall thickness & $0.014 \mathrm{~m}\left(0.545^{\prime \prime}\right)$ \\
\hline $\begin{array}{l}\text { Casing length (packer to packer) } \\
\text { - Production Zone } \\
\text { - } \quad \text { Dumping Zone }\end{array}$ & $\begin{array}{l}15.240 \mathrm{~m}\left(50^{\prime}\right) \\
13.41 \mathrm{~m}\left(44^{\prime}\right)\end{array}$ \\
\hline Inner tubing OD at Production Zone & $0.089 \mathrm{~m}(3.5 ”)$ \\
\hline Perforation & 12 shots per foot \\
\hline Separator Inlet diameter & $0.0105 \mathrm{~m}$ \\
\hline Separator Outlet diameter & 0.15 \\
\hline
\end{tabular}

\section{NUMERICAL IMPLEMENTATION}

The production zone and the dumping zone have been modelled and simulated separately.

\subsection{Modelling process}

A 3D model of each zone was generated using ANSYS Design Modeller. The dimensions shown in Table 1 has been first utilized to generate a 2D plane model of vertical cross-section. The plane was then revolved into a 3D solid model. To introduce the perforation holes on the well wall, the flow outlets were drawn at a separate plane and then cut out from the solid wellbore model and introduced in the main wall model. The completed 3D models for the production zone and the dumping zone are shown in Figs 3(a) and 3(b). The perforation orientation is shown in Fig. 3(c). Figs 2(a) and 2(b) give a clear representation of the inlets and outlets of these zones. For the production zone.

\subsection{Mesh generation}

In the mesh generation stage, the inlets and outlets of the model, the sizing, smoothing, inflation and all other mesh options were set. For the production zone, the inlets were the perforated holes in the casing wall and the outlets were the separator inlets. For the dumping zone, the inlets were the separator outlet and the outlets were the perforated holes in the casing wall. Table 2 shows the mesh setting used to create mesh model. Other elements unspecified have been set by the default setting of the program. The statistics for the initial mesh model is 349,690 nodes and 1,832,214 elements. Fig. 3 display a meshed portion of the model. 
Table 2: Final selection of meshes after the independency check.

\begin{tabular}{|l|c|c|}
\hline \multicolumn{1}{|c|}{ Mesh parameter } & $\begin{array}{c}\text { Production } \\
\text { Zone Values }\end{array}$ & $\begin{array}{c}\text { Dumping Zone } \\
\text { Values }\end{array}$ \\
\hline Assembly Meshing Method & Tetrahedrons & Tetrahedrons \\
\hline Nodes & 246,251 & 253,615 \\
\hline Elements & 687,246 & $1,338,868$ \\
\hline
\end{tabular}

\subsection{Mesh quality}

For both production and dumping zone models, three primary factors have been considered to evaluate the mesh quality which are skewness, aspect ratio and orthogonal quality.

Skewness is a primary indicator for quality measures for the cells in a mesh. It is valued between 0.0 and 1.0. It could be computed directly based on the mesh built. The average skewness of the models was 0.24 and 0.30 , respectively which falls under excellent category.

The orthogonal quality for cells is computed using the face normal vector, the vector from the cell centroid to the centroid of each of the adjacent cells, and the vector from the cell centroid to each of the faces. The worst cells would have an orthogonal quality closer to 0.0 while the best cells would have an orthogonal quality closer to 1.0. The average orthogonal quality calculated for the mesh of the production zone and dumping zone models are equal at 0.85 hence it is very good.

The aspect ratio is a measure of the stretching of a cell. The mean aspect ratios for the production zone and for the dumping zone are $\sim 2.0$ and $\sim 5.0$, respectively which are representing good mesh quality.

Based on the three main elements: skewness, orthogonal quality and aspect ratio, the generated meshes are accepted and highly satisfactory to run truthful simulation.

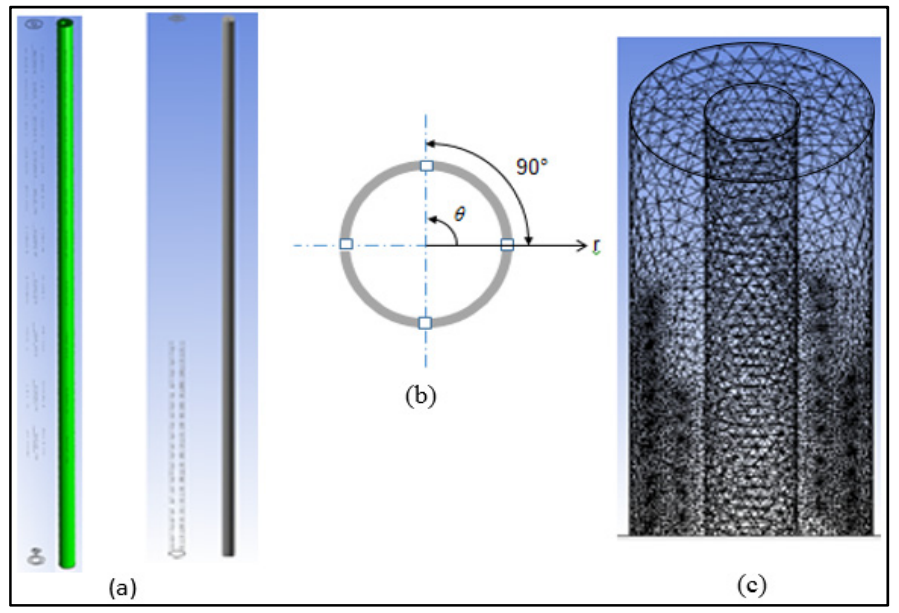

Figure 3: Computational modelling of the well. (a) The 3-D models of the production zone and the dumping zone; (b) Horizontal cross-section of the production tubing at the perforated holes section; (c) Mesh model of the top part of the wellbore. 
Table 3: Boundary conditions inputs to the simulation of the production and the dumping zones.

\begin{tabular}{|c|c|c|}
\hline \multirow{2}{*}{ Boundary Condition } & \multicolumn{2}{|c|}{ values } \\
\cline { 2 - 3 } & In the production zone & In the dumping zone \\
\hline Inlet relative pressure & $12,776 \mathrm{kPa}$ & $8,184.08 \mathrm{kPa}$ \\
\hline Outlet relative pressure & $620.53 \mathrm{kPa}$ & $8,053.08 \mathrm{kPa}$ \\
\hline $\begin{array}{c}\text { Turbulence intensity at } \\
\text { inlet }\end{array}$ & $10 \%$ & $10 \%$ \\
\hline Gravity $(\mathrm{x}, \mathrm{y}, \mathrm{z})$ & $(0,-9.81,0) \mathrm{m} / \mathrm{s}^{2}$ & $(0,-9.81,0) \mathrm{m} / \mathrm{s}^{2}$ \\
\hline
\end{tabular}

\subsection{Boundary conditions}

The fluid properties were adopted from a major well in offshore field in Malaysia. Density and viscosity of water were $1000 \mathrm{~kg} / \mathrm{m} 3$ and $0.00097 \mathrm{~kg} / \mathrm{m}-\mathrm{s}$, respectively. Density and viscosity of the hydrocarbon were $840 \mathrm{~kg} / \mathrm{m} 3$ and $0.00045 \mathrm{~kg} / \mathrm{m}-\mathrm{s}$, respectively. The flow rate, as per the well production, was $3.036 \times 10-4 \mathrm{~m} 3 / \mathrm{s}$. Table 3 shows the boundary conditions for the setup input into the numerical solution, as adopted from the real well in offshore field in Malaysia.

\section{RESULTS AND DISCUSSIONS}

Four different oil-to-water concentrations in the mixture as 30-70, 50-50, 70-30 and 90-10 were simulated. With the assumption that the separator performance efficiency is at $90 \%$, the variation of oil content in the water outflow could be calculated and the results are shown in Table 4.

\subsection{Validation of simulation results}

The simulation results have been validated by comparing the densities values of the mixture in as obtained from the simulation with the well-established formula for the rule of mixture.

$$
\rho_{\text {theory }}=c_{\text {oil }} \rho_{\text {oil }}+\left(1-c_{\text {oil }}\right) \rho_{\text {water }}
$$

Table 4: Tested cases of the oil-to-water ratios in the produced mixture.

\begin{tabular}{|c|c|c|c|}
\hline Case & $\begin{array}{c}\text { Oil-to-Water } \\
\text { Production Ratio }\end{array}$ & $\begin{array}{c}\text { Post-Separator Oil-to- } \\
\text { Water Ratio @ Water } \\
\text { Outlet }\end{array}$ & $\begin{array}{c}\text { Mean oil volume } \\
\text { fraction, } \beta\end{array}$ \\
\hline 1 & $30: 70$ & $5: 95$ & 0.05 \\
\hline 2 & $50: 50$ & $10: 90$ & 0.10 \\
\hline 3 & $70: 30$ & $21: 79$ & 0.21 \\
\hline 4 & $90: 10$ & $50: 50$ & 0.50 \\
\hline
\end{tabular}


Eqn (1) is a common one that used to estimate the mixture density $\rho_{\text {theory }}$ where $c_{\text {oil }}$ is the oil volume fraction in the oil/water mixture, $\rho_{\text {oil }}$ is the density of oil and $\rho_{\text {water }}$ is the density of water in the oil/water mixture. The maximum relative error between the predicted densities by the simulation and the role of mixture correlations are $2.4 \%$ at $90 \%$ oil content in the production zone, and $1.9 \%$ at $50 \%$ oil content in the dumping zone.

\subsection{Results of density distribution}

\subsubsection{Analysis of density distribution at the production zone}

At the production zone, oil and water flow enters the wellbore through the perforated holes. Fig. 4 shows the density distribution of two cases: $30 \%$ and $90 \%$ oil content, at both the perforated holes section and the outlet section. At $30 \%$ oil content, the average density at perforated holes section is $957.33 \mathrm{~kg} / \mathrm{m} 3$ and at the outlet section is $952.00 \mathrm{~kg} / \mathrm{m} 3$, with difference of only $0.56 \%$. At $90 \%$ oil content, the difference between the average densities at the two sections is $3.21 \%$. At the perforated holes section, the inflow of oil and water causes high turbulence in the flow. Jets of mixture going into the wellbore prevent the mixture from settling. As the flow moves to the bottom of the production zone towards the area without perforated holes, the mixture tends to settle due to gravitational force.

Visualization of the oil/water mixture for all cases with varied oil content, as predicted by the simulation, is shown in Fig. 5 in terms of density distribution, with red being pure oil and dark blue being pure water.

Three locations in the production zone of the well are referred: $0.0 \mathrm{~m}, 7.0 \mathrm{~m}$ and $14.0 \mathrm{~m}$ from the bottom of the zone and each zone is taken for approximately $0.5 \mathrm{~m}$ in height. In the upper location of the zone, there are 28 perforated holes for production inflow. At $90.0 \%$ oil content, the simulation in the upper location of the production zone reveals that there are no spots with pure oil or pure water.

But the mixture structure is changing at the bottom of the upper zone where the perforations are located, where it is clear that lower density portions are produced. In the middle location of the zone, there are 40 perforated holes for production inflow where the holes are evenly spaced across the height of the sampling area.

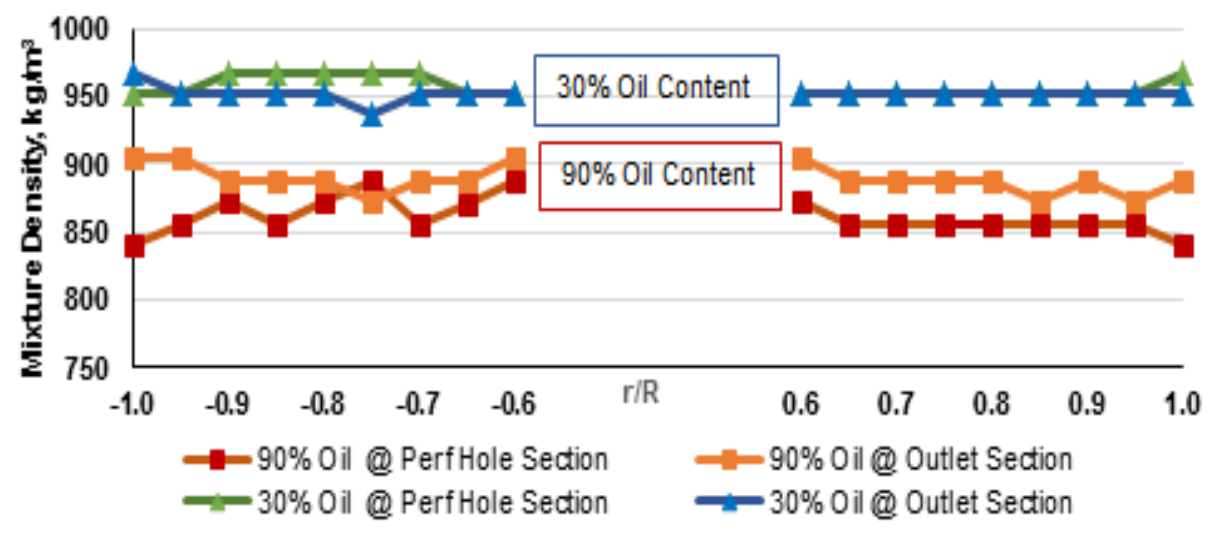

Figure 4: Density distribution at $30 \%$ and $90 \%$ oil concentration, at upper and lower sections in the production zone. 


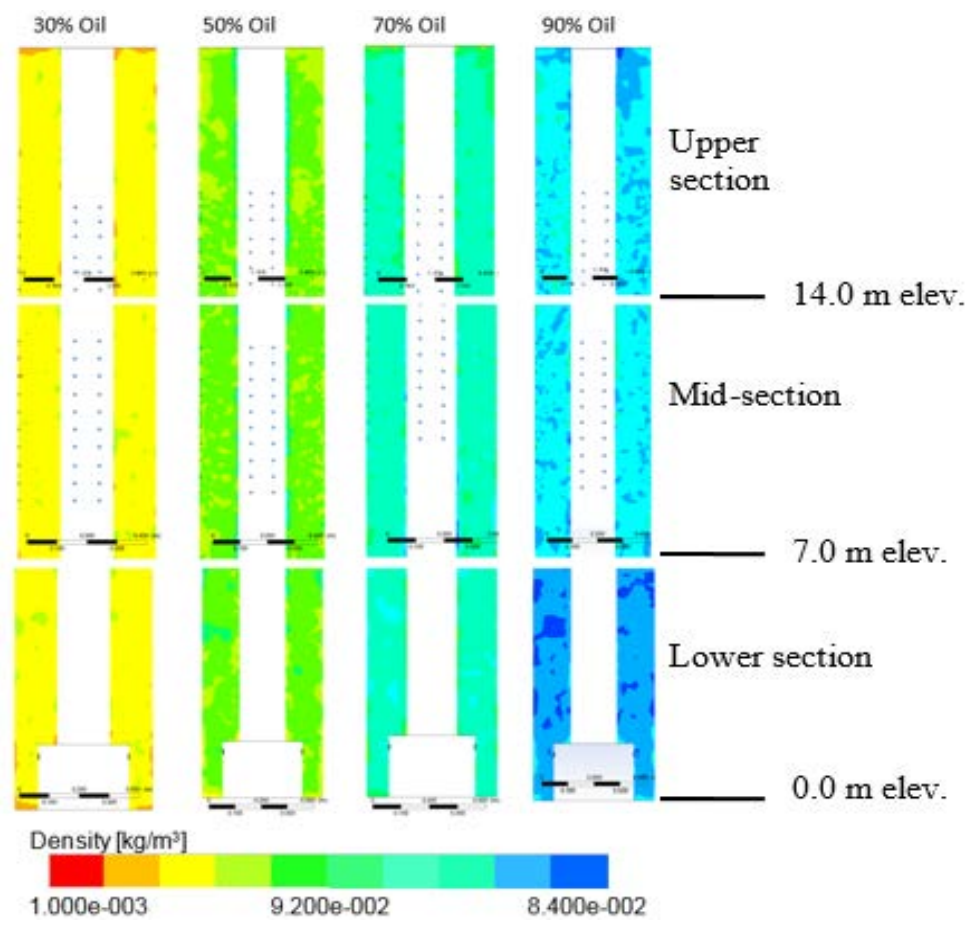

Figure 5: The predicted density distribution of oil inside the wellbore at different oil content in the production zone.

For all cases, the mixture in the middle section is more homogenous as compared to the mixture in the bottom section. This is mainly due to the high turbulence and the jet of the mixture from the perforating holes in the middle section which impact on the production tube.

\subsubsection{Analysis of density distribution at the dumping zone}

At the dumping zone, water flows out of the separator outlet containing a little amount of oil. The density results have been compared for two cases of minimum and maximum oil content in water: 5\% and 50\%. The contour results are shown in Fig. 6. For both cases, the density profiles show that the mixture is uniformly mixed at the wellbore length section without perforated holes. As the flow moves downwards to the dumping section, there are changes in the mixture density, at $2.5 \mathrm{~m}$ and $5.0 \mathrm{~m}$ from the wellbore bottom.

With $5.0 \%$ oil content, mixture is even along the wellbore except at the perforated holes section where the flow is water dominated. With $50.0 \%$ oil content, the flow is still water dominated at the holes section. However, the density at the wellbore centre is not even. There are portions of the mixture that contain more oil (lower than average density) or more water (higher than average density). The difference between the two cases of minimum and maximum oil content is that with $50 \%$ oil, the turbulence-induced interaction between oil and water is significant. The occurrence is visualised clearly in the contours shown in Figs 6(a) and $6(\mathrm{~b})$. 


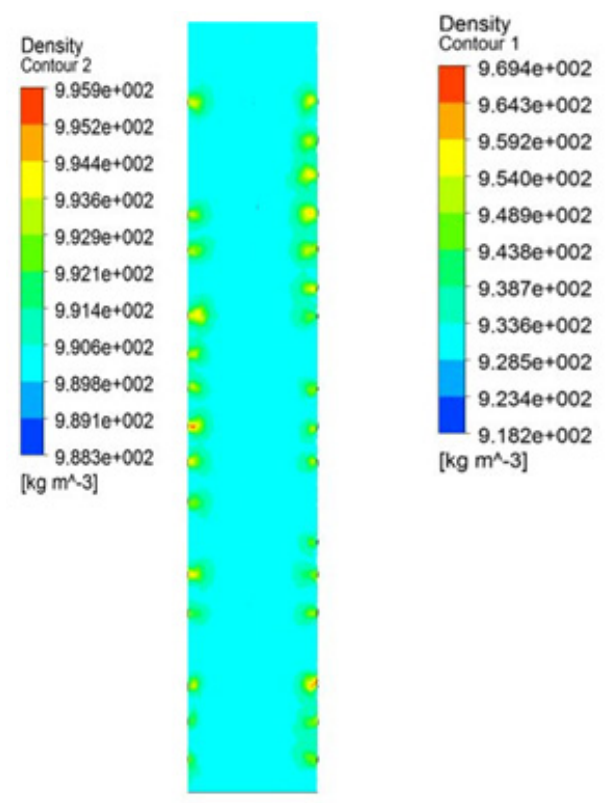

(a)

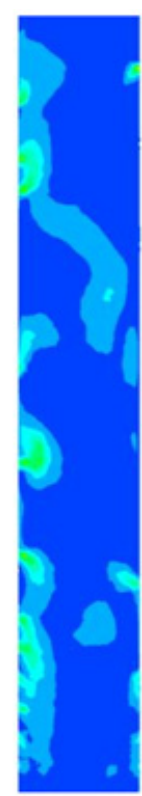

(b)

Figure 6: Density contours at the perforated holes section in the dumping zone for, (a) $5 \%$ and (b) $50 \%$ oil content.

\subsection{Volume fraction results}

\subsubsection{Volume fraction distribution at the production zone}

At the production zone, the oil volume fraction inside the mixture is uniform throughout the entire wellbore length for the case of $30 \%$ oil. When the oil content increased to $50 \%, 70 \%$, and $90 \%$, oil volume fraction increased at the bottom section of the zone, making the difference between the top and bottom sections more visible, as shown in Fig. 7(a). When oil content in the mixture is less than or equals $50 \%$, the volume fraction distribution of oil is uniform at both the perforated holes section and bottom where flow is going into the separator. The high turbulence of the production inflow prevents the flow from settling. In the cases of $90 \%$ oil content, the effect of gravitational force is more apparent where the mixture is more settled at the bottom of the zone. However, while oil content is high, there is no notable area in the flow where the mixture is pure water or pure oil.

\subsubsection{Analysis of volume fraction distribution at the dumping zone}

At the dumping zone, the mixture of oil and water flow into the zone from the separator outlet. The mixture moves out of the zone through the perforated holes. The volume of oil in the mixture is insignificant to affect its interaction with the water. For the other cases from $\beta$ $=0.1$ to $\beta=0.5$, the oil droplets are more concentrated around the edge of the wellbore. This may be due to the high turbulence caused by the inflow from the separator outlet, forcing the oil droplets to migrate to the edge of the wellbore. It could be explained by the effect of hydrodynamic forces acting on the droplets. Consider an oil droplet located away from the wellbore centre. 


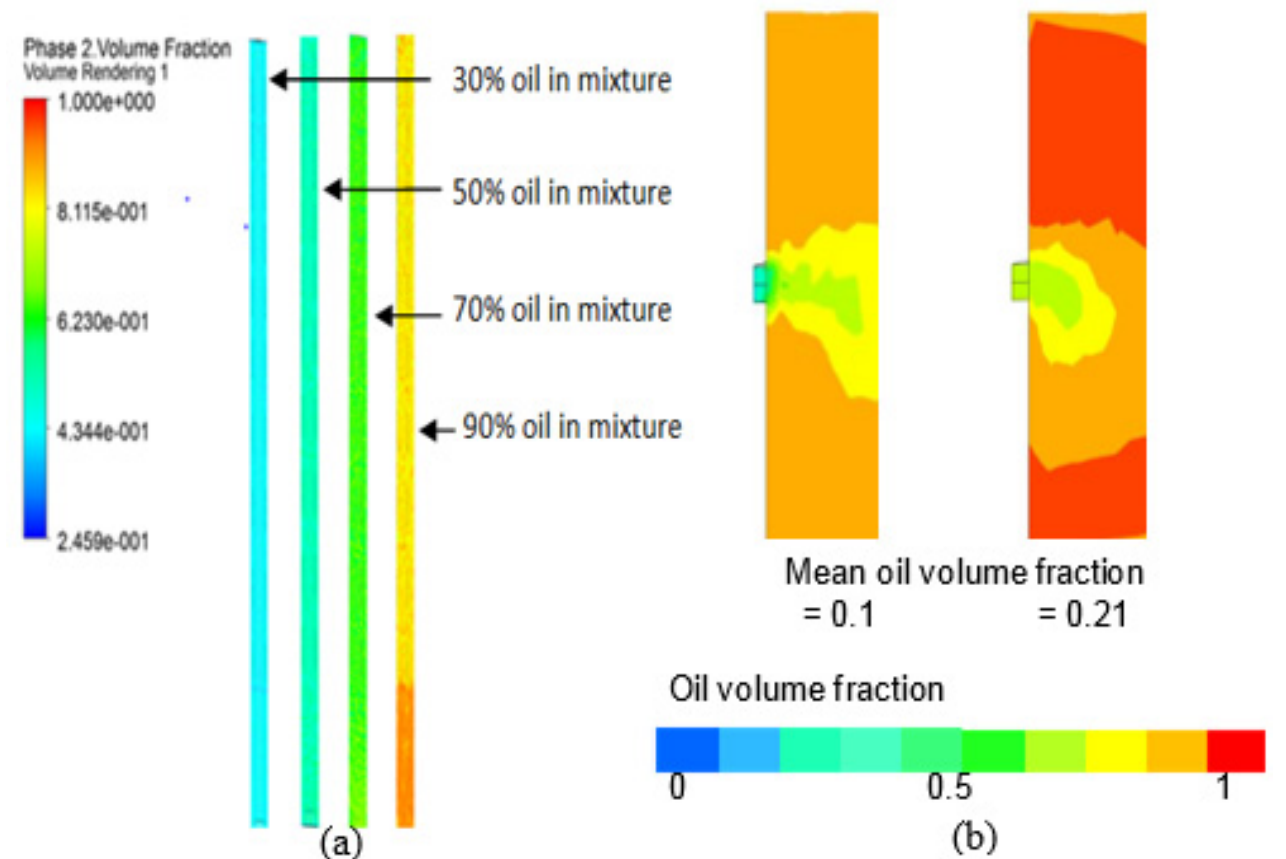

Figure 7: (a) Oil volume fraction for (left to right) $30 \%, 50 \%, 70 \%$ and $90 \%$ oil content in the production zone; (b) Oil volume fraction contour at the separator outlet for 0.1 and 0.21 oil content.

If turbulence in the flow causes the oil droplet to move slightly toward the wall, the mixture incompressibility means that an equivalent volume of water must move slightly towards the wellbore centre. Since water has a higher density than oil, the overall kinetic energy of the system is now reduced and the system is in a lower energy state. Now consider an oil droplet at the wellbore wall. If the oil droplet were to move away from the wall this would require an input of energy to the system. There is thus a natural tendency $(\beta>0.05)$ for the system to move towards a lower energy state, resulting in oil droplets moving towards the wellbore wall - and once they are at the wall they tend to remain there (Lukas and Panagiotopoulos [11]). This phenomenon is visualized with the contour in Fig. 7(b).

\section{CONCLUSIONS}

A wellbore production and dumping zone is designed and modelled by CFD technique using ANSYS-Fluent 14 software. The simulation has been performed at various oil/water volume fractions. Results revealed that in the production zone, the oil volume fraction distribution depends highly on the mean oil volume fraction and the horizontal length of the zone without perforations. The contour results from the simulation show that the phases mix and achieve uniform distribution as the mixture proceeds flowing to down of the annulus. In the dumping zone, the distribution is generally uniform for all cases in the entire wellbore length except at areas very near the separator outlet and at perforated holes. There is zero oil content present at the holes for water dumping. 
In general, the results illustrate the great complexity of oil/water mixture flows, reflecting the many competing parameters, such as turbulence, gravitational separation droplet interaction and the shear between the two liquids and with the solid surfaces, which are occurring in the production annulus zone in the downhole. The simulation results presented serve mainly to illustrate the complexity of the oil and water mixture in the oil producing well. Also, presented and discussed the numerical simulation quality parameters. The simulation results could be used to better predict the behaviour of oil/water mixture flow inside the wellbores with the presence of a one, two and multi inlets hydrocyclone.

\section{ACKNOWLEDGEMENT}

The authors acknowledge Universiti Teknologi PETRONAS for the financial and technical support to produce this paper under the research grant YUTP - FRG 015-3AA-A73.

\section{REFERENCES}

[1] Shaw, C. \& Fox, M., Economics of Downhole Oil-Water Separation: A Case History and Implications for the North Sea. European Petroleum Conference, 20-22 October, The Hague, Netherlands, SPE-50618-MS, 1998.

[2] Ouyang, L. B. \& Aziz, K., A general single-phase wellbore/reservoir coupling model for multilateral wells. SPE Reservoir Evaluation \& Engineering, 4(4), pp. 327-335, SPE 72467-PA, 2001.

[3] Ahmed, M.M. \& Ayoub, M.A., A comprehensive study on the current pressure drop calculation in multiphase vertical wells; current trends and future perspective. Journal of Applied Sciences, 14, pp. 3162-3171, 2014.

[4] Tubel, P. \& Herbert, P., Intelligent Systems for Monitoring and Control of Downhole Oil-Water Separation, SPE 49186, 1998.

[5] Swisher, M. \& Wojtanoviez, A., New Dual Completion Method Eliminated Bottom Water Coning, SPE 30697, 1995.

[6] Yin, K.Y., Al-Kayiem, H.H. \& Pao, W., Numerical study of water control with downhole oil-water separation technology, MATEC Web of Conferences 13, 02029, 2014.

[7] Veil, J.A. \& Quinn, J., Performance of Downhole Separation Technology and Its Relationship to Geologic Conditions, SPE/EPA/DOE Exploration and Production Environmental Conference, Texas, SPE 93920, 2005.

[8] Bowers, B.E., Brownlee, R.F. \& Schrenkel, P.J. Development of a downhole oil/water separation and reinjection system for offshore application. Peak Process, Inc. Chevron Petroleum Technology Co; and SPE, REDA, 2000.

[9] Harrison, O., Al-Kayiem, H.H. \& Hashim, F. M., Numerical studies on the separation performance of liquid-liquid Hydrocyclone for higher water-cut wells. IOP Conference Series: Materials Science and Engineering 12/2015, 100(1), 012014, 2014.

[10] Harrison, O., Al-Kayiem, H.H. \& Hashim, F.M., Theoretical background and the flow fields in downhole liquid-liquid hydrocyclone (LLHC). MATEC Web of Conferences 12:02032, 2014.

[11] Lucas, G. P. \& Panagiotopoulos, N., Measurement and Modelling of Oil Volume Fraction and Velocity Profiles in Vertical, Bubbly Oil-in-Water Flows, 11th Int. Conf. on Multiphase Flow in Industrial Plants, Palermo, Italy, 2008. 